\title{
PENGARUH WORK FAMILY CONFLICT DAN KEPUASAN KERJA TERHADAP KOMITMEN ORGANISASIONAL KARYAWAN PT. PASIFIC EXPRESS GARMENT
}

\author{
Pasek Putu Agung Wendhastra Dura Dharsana ${ }^{1}$ \\ I Made Artha Wibawa ${ }^{2}$ \\ ${ }^{1,2}$ Fakultas Ekonomi dan Bisnis Universitas Udayana, Bali, Indonesia \\ email: agungdret23@gmail.com
}

\begin{abstract}
ABSTRAK
Perusahaan mempunyai peran yang sangatlah vital didalam menolong pegawai dalam membentuk komitmen organisasional. Tujuan penelitian yaitu agar tahu pengaruh dari work family conflict serta kepuasan kerja pada komitmen organisasional di PT. Pasific Express Garment Denpasar. Sample dipakai sejumlah 45 orang menggunakan tehnik sampling jenuh. Pengumpulan data dilaksanakan dengan penyebaran kuisioner secara langsung pada pegawai PT. Pasific Express Garment Denpasar serta analisis memakai statistik dekriptif rata-rata hitung juga statistik deskriptif seperti uji asumsi klasik serta analisis regresi linear berganda. Hasil analisis data menunjukkan bahwa variabel work-family conflict berpengaruh negatif dan signifikan terhadap komitmen organisasional karyawan PT. Pasific Express Garment Denpasar dan variable Kepuasan Kerja memiliki pengaruh positif pada Komitmen Organisasional pegawai PT. Pasific Express Garment Denpasar.
\end{abstract}

Kata kunci : Komitmen organisasional, kepuasan kerja, work-family conflict.

\begin{abstract}
Organizations hold a very important key in helping employees to build organizational commitment. The purpose of the study was to analyze, to determine the effect of work family conflict and job satisfaction on organizational commitment at PT. Pacific Express Garment Denpasar. The sample was determined by 45 people with saturated sampling techniques. Data collection is done by distributing questionnaires directly to employees of PT. Pacific Express Garment Denpasar and analyzed using descriptive statistics on average counts and descriptive statistics in the form of classic assumption tests and multiple linear regression analysis. The results of data analysis showed that work-family conflict variables had a negative and significant effect on the organizational commitment of employees of PT. Pacific Denpasar Garment Garment and Job Satisfaction variables have a positive effect on Organizational Commitment of employees of PT. Pacific Express Garment Denpasar. Keyword : Organizational commitment, job satisfaction, work-family conflict.
\end{abstract}




\section{PENDAHULUAN}

Perusahaan mempunyai peran yang sangatlah vital didalam menolong pegawai dalam membentuk komitmen organisasional. Salah satunya melalui dukungan organisasi, pernyataan tersebut ditegaskan kembali pada riset (Hidayati, et al., 2011) yang memberikan pernyataan bahwasannya peran organisasi mempunyai hubungan dengan komitmen organisasional. Setelah organisasi yang memberi dukungan, menjadi vital pula agar memberikan perhatian daripada sisi individunya juga, yang mana tiap-tiap individu pula mempunyai fungsi dalam mempunyai komitmen organisasional yang besar supaya bisa kerjasama dengan perusahaan serta mendapat hasil prestasi terbaik (Hidayati et al., 2011).

Sebuah perusahaan perlu sebuah sistim yang bisa melakukan penunjangan komitmen organisasi itu. Mencapai tujuan perusahaan perlu adanya kerjasama yang bagus diantara unsur didalamnya (Khatibi et al., 2009). Helena and Praveen (2008) memberi pernyataan komitmen organisasi jadi perihal yang vital pada suatu perusahaan supaya bisa mengarah menuju tujuan yang sudah ditentukan. Komitmen bercermin tingkat kesetiaan individual kepada profesi cocok dengan persepsi bagi individual itu hingga pegawai bisa memberikan pelayanan terbaik.

Komitmen organisasional didefinisikan sebagai ikatan psikologis individu dengan organisasi, yang dapat ditunjukan oleh berbagai indikator, seperti memiliki loyalitas terhadap organisasi, internalisasi tujuan organisasi, dan mendedikasikan diri pada tujuan organisasi Crowet et al., (2012). Komitmen organisasional adalah sikap kerja yang penting karena orang-orang yang memiliki komitmen diharapkan bisa menunjukkan kesediaan untuk bekerja lebih keras demi mencapai tujuan organisasi dan memiliki hasrat yang lebih besar untuk tetap bekerja di suatu organisasi (Kreitner dan Kinicki, 2014: 165). Definisi komitmen organisasional dalam penelitian ini mengarah kepada teori dari Allen dan Meyer (1990) yang mengatakan bahwa karyawan yang memiliki komitmen akan bekerja penuh dedikasi, yang membuat karyawan memiliki keinginan untuk memberikan tenaga dan tanggung jawab yang lebih untuk menyokong kesejahteraan dan keberhasilan organisasi tempatnya bekerja.

Faktor-faktor yang bisa membuat pegawai mempunyai komitmen organisasional ataupun tidak salah satunya adalah work family conflict. Bekerja serta menghabiskan waktu dengan keluarga adalah dua hal penting didalam hidup orang dewasa yang memiliki pekerjaan (Acha, 2013), untuk pria ataupun wanita. (Utami et al., 2014) memberikan pernyataan berperan aktif didalam dua-duanya memberikan sebab adanya peran ganda, peran didalam kerja (sebagai pegawai) serta peran didalam keluarga pula (sebagai istri, suami, juga orangtua), dikarenakan hal tersebut melakukan penyeimbangan tuntutan didalam berperan bekerja juga berperan keluarga yang ditanggung, adalah tugas vital pegawai yang sudah berkeluarga agar meminimalisir konflik.

Kopelman et al., (1983) mendefinisikan work conflict (konflik pekerjaan) sebagai suatutingkat di mana seseorang mengalami tekanan ketidak-seimbangan dalam bidang pekerjaan. Konflik ini terjadi jika seseorang mengalami stres dalam melakukan pekerjaannya sehari-hari. Sedangkan family conflict (konflik keluarga) merupakan tingkat di mana seseorang mengalami tekanan ketidak seimbangan dalam bidang keluarga. Frone et al., (1992) menjelaskan lebih lanjut bahwa work- 
family conflict terjadi karena karyawan berusaha untuk menyeimbangkan antara permintaan dan tekanan yang timbul, baik dari keluarga maupun dari pekerjaannya. Cinamon et al., (2002) dalam penelitiannya pada profesi guru menjelaskan bahwa jumlah anak, jumlah waktu yang dihabiskan untuk mengurus rumah tangga dan pekerjaan serta tidak adanya dukungan dari pasangan dan keluarga merupakan pemicu terjadinya konflik pekerjaan-keluarga

Pernyataan tersebut ditunjukkan oleh riset dari Senem and Ozgur (2013) yang memperoleh hasil penelitian bahwasannya komitmen organisasional akanlah terpengaruh oleh dimana work-family conflict dimana work-family conflict akanlah memberikan pengaruh tak bagus pada komitmen organisasional pegawai. Hasil yang sama diperoleh Luo Lu et al., (2009) yang memberikan pernyataan komitmen organisasional akanlah terpengaruh oleh konflik kerja-keluarga dimana konflik kerja-keluarga dapat memberikan pengaruh negative pada komitmen organisasional karyawan. Konflik kerja-keluarga makin sering diperdebatkan karena naiknya partisipasi orang didalam dunia pekerjaan.

Kepuasan kerja karyawan perlu mendapat perhatian lebih guna meningkatkan komitmen karyawan (Thoyib dkk., 2012). Riset Thomas Stefanus Kaihatu dan Wahju Astjarjo Rini (2007) memberi petunjuk bahwasannya kepuasan kerja memiliki pengaruh yang signifikan pada komitmen organisasional. Hasil riset tersebut konsisten dengan riset Vandenberg dan Lance (1992); Knoop (1995) bahwasannya kepuasan akanlah kualitas pekerjaan adalah aspek prediksi yang vial pada komitmen organisasi didalam (Thomas Stefanus Kaihatu dan WahjuAstjarjo Rini, 2007). Dikarenakan hal tersebut, bila seorang sudah mendapatkan rasa puas pada hasil kerja jadi dapat dibentuk asumsi individual itu dapat mempunyai komitmen yang besar pada kerjaannya. Namun bila rasa puas didalam diri seseorang pada pekerjaan turun mampu membuat penurunan tertariknya individual pada kerjaannya.

Kepuasan kerja merupakan sesuatu bersifat individual dan setiap individu memiliki tingkat kepuasan berbeda sesuai sistem nilai yang berlaku pada dirinya. (Rivai dan Sagala, 2011:856). Kepuasan kerja adalah tanggapan afektif atau emosional berbagai segi pekerjaan seseorang (Kreitner dan Kinicki, 2014:169). Kepuasan kerja adalah perasaan positif seorang karyawan yang merupakan hasil dari evaluasi karakteristik pribadi karyawan, seorang karyawan dengan kepuasan kerja yang tinggi memiliki perasaan-perasaan positif tentang pekerjaan tersebut, sementara seorang karyawan yang merasakan ketidakpuasan dengan pekerjaan mereka memiliki perasaan-perasaan yang negatif pada pekerjaannya (Robbins \& Judge, 2009 : 99). Dampak positif dari seorang karyawan yang merasakan kepuasan kerja salah satunya adalah menurunnya keinginan dari karyawan untuk berhenti dari perusahaan (Suhanto, 2009).

Penelitian ini mengambil lokasi di PT. Pasific Express Garment Denpasar yang bergerak dalam bidang produksi yang menggunakan sumber daya manusia sebagai tenaga kerja yang tentu memperhatikan kinerja karyawannya. Kendala yang masih sering ditemukan dalam pelaksanaan adalah lemahnya sumber daya manusia sebagai unsur potensial yang mampu berkarya. Kondisi sosial budaya perlu dikenali dan ditingkatkan untuk mendapatkan tenaga profesional dan beretika serta memiliki disiplin tinggi. Oleh karena itu komitmen organisasional 
mempunyai fungsi vital didalam berhasilnya kerja seseorang pegawai didalam sebuah perusahaan. Komitmen organisasional pegawai yang kecil di perusahaan mampu memberi dampak untuk pegawai tersebut sendiri serta pada perusahaan. Komitmen organisasional pegawai yang besar di perusahaan dapat memberikan dampak kinerjanya meninggi, tingkat absen menguranurang, pegawai setia juga lain sebagainya. Disamping itu, komitmen organisasional pula memberi pengaruh pada efektivitas serta efisiensi organisasi.

Pada kondisi sebenarnya di PT. Pasific Express Garment Denpasar menurut pengamatan peneliti, ada masalah adalah rendah atau tingginya komitmen organisasional karyawan di PT. Pasific Express Garment Denpasar. Hasil wawancara dari 5 orang karyawan produksi bahwa sangat memerlukan karyawan yang memiliki loyalitas tinggi dalam perusahaan agar dapat bekerja lebih efektif dalam mencapai tujuan perusahaan, namun hal itu masih belum dapat direalisasikan karena masih ada beberapa karyawan yang melakukan tindakantindakan yang kurang mematuhi aturan yang menyebabkan terjadinya keluhankeluhan pelanggan seperti karyawan yang kurang cepat melayani pelanggan dan sering terdapat keterlambatan waktu yang tidak sesuai dengan ketentuan pelanggan.

Dilihat dari Tabel 1. pada jumlah persentase tingkat absensi tahun 2017 masih dianggap kurang baik karena memiliki nilai rata-rata sebesar 4.1\%. Banyak faktor yang menyebabkan karyawan tidak masuk kerja, seperti sakit, upacara agama, ijin, dan bahkan membolos. Dengan banyaknya karyawan yang tidak hadir membuat terjadinya keterlambatan produksi yang sudah di tentukan pelanggan. Jika merujuk kepernyataan Edwin B. Flippo (2001) persentase absensi diatas 3 persen sampai 10 persen dinyatakan tinggi.

Hal yang menyebabkan persentase tingkat absensi tinggi, karena karyawan PT. Pasific Express Garment Denpasar setiap bulannya ada yang tidak hadir dengan berbagai alasan. Kurang fokusnya karyawan dalam melaksanakan pekerjaannya disebabkan adanya permasalahan dalam keluarga yang mengurangi konsentrasi untuk menyelesaikan pekerjaan, perbedaan tanggung jawab membuat bingung, sehingga menunjukan sikap yang berbeda pada kedua peran yaitu sebagai karyawan di perusahaan dan sebagai anggota keluarga. Kondisi tersebut yang membuat absensi karyawan produksi PT. Pasific Express Garment Denpasar dianggap kurang baik karena memiliki nilai rata-rata sebesar $4.1 \%$.

Pegawai pula menyebut bahwasannya tidak adanya pendukung sumber dana yang diperoleh bila pegawai melaksanakan pekerjaan lebih, ide, pendapat, saran daripada pegawai masihlah tidak dihitung, balasan atas jasa yang didapat dirasakan masih kurang serta tidak cocok dengan pertanggung jawaban yang diterima pegawai. Masalah didalam mengelola SDM khusus didalam pembinaan komitmen organisasional pegawai PT. Pasific Express Garment Denpasar yang bergerak dalam bidang produksi yang menggunakan sumber daya manusia sebagai tenaga kerja tentu memiliki komitmen didalam pekerjaan yang akanlah memberi dukungan aktivitas perusahaan. 
Tabel 1.

Tingkat Absensi Karyawan Produksi PT. Pasific Express Garment Denpasar Tahun 2018

\begin{tabular}{|c|c|c|c|c|c|c|}
\hline Bulan & $\begin{array}{l}\text { Jumlah } \\
\text { Pegawai }\end{array}$ & $\begin{array}{c}\text { Jumlah } \\
\text { Hari } \\
\text { Kerja } \\
\text { Efektif }\end{array}$ & $\begin{array}{c}\text { Total } \\
\text { Hari } \\
\text { Kerja } \\
\text { Efektif/ } \\
\text { Bulan } \\
\end{array}$ & $\begin{array}{c}\text { Total } \\
\text { Absensi }\end{array}$ & $\begin{array}{c}\text { Jumlah Hari } \\
\text { Kerja } \\
\text { Terpenuhi/Bulan }\end{array}$ & $\begin{array}{c}\text { Persentase } \\
\text { Tingkat } \\
\text { Absensi (\%) }\end{array}$ \\
\hline
\end{tabular}

\begin{tabular}{|c|c|c|c|c|c|c|}
\hline $\mathbf{A}$ & B & $\mathbf{C}$ & $D=B x C$ & $\mathbf{E}$ & $F=D-E$ & $\mathrm{G}=\mathrm{E} / \mathrm{D} .100$ \\
\hline Januari & 45 & 23 & 1035 & 36 & 999 & 3.5 \\
\hline Februari & 45 & 24 & 1080 & 41 & 1039 & 3.8 \\
\hline Maret & 45 & 25 & 1125 & 47 & 1078 & 4.2 \\
\hline April & 45 & 21 & 945 & 38 & 907 & 4.0 \\
\hline Mei & 45 & 25 & 1125 & 54 & 1071 & 4.8 \\
\hline Juni & 45 & 26 & 1170 & 44 & 1126 & 3.8 \\
\hline Juli & 45 & 26 & 1170 & 52 & 1118 & 4.4 \\
\hline Agustus & 45 & 24 & 1080 & 22 & 1058 & 2.0 \\
\hline September & 45 & 26 & 1170 & 50 & 1120 & 4.3 \\
\hline Oktober & 45 & 25 & 1125 & 57 & 1068 & 5.1 \\
\hline November & 45 & 23 & 1035 & 39 & 996 & 3.8 \\
\hline Desember & 45 & 25 & 1125 & 64 & 1061 & 5.7 \\
\hline \multicolumn{2}{|c|}{ Jumlah } & & & & & 49.3 \\
\hline \multicolumn{2}{|c|}{ Rata-rata } & & & & & 4.1 \\
\hline
\end{tabular}

Sumber : PT. Pasific Express Garment Denpasar, 2018

Rehman \& Waheed, (2012) didalam risetnya di perguruan-perguruan tinggi negeri serta swasta Pakistan menghasilkan bahwa berdampak negative diantara $W F C$ dengan komitmen organisasional, yang mana anggota fakultas yang telah berkeluarga mempunyai tingkat WFC yang lebih besar dibanding dengan yang mempunyai status lajang, anggota fakultas yang telah berkeluarga mempunyai $W F C$ yang besar mampu mengecilkan komitmen organisasi. Hasil yang sama pula terungkap oleh Boles et al. (2001) yang man WFC memberikan penurunan prestasi kerja pegawai, turunnya prestasi kerja pegawai mampu berdampak di turunnya komitmen organisasi. Hasil tersebut diperkuat oleh Balmforth \& Gardner, (2006) memberi petunjuk bahwasannya WFC mempunyai hubungan negative dengan komitmen organisasional. Hubungan negative diantara WFC serta komitmen organisasional terlihat di pegawai yang merasakan sulitnya didalam membuat selaras perannya pada keluarganya ataupun pada pekerjaannya akanlah merasakan kurangnya komitmen pada organisasi.

Penelitian Senem and Ozgur (2013) yang memberi pernyataan bahwasannya komitmen organisasional akanlah terpengaruhi oleh konflik kerja-keluarga yaitu konflik kerja-keluarga akanlah membawakan pengaruh tiidak baik pada komitmen organisasional pegawai. Pernyataan berikut sama dengan riset Luo Lu et al., (2009) yang memberi pernyataan bahwasannya komitmen organisasional akanlah terpengaruhi oleh WFC yang mana $W F C$ akan membawa pengaruh negative 
terhadap komitmen organisasional karyawan. WFC makin banyaknya berbincang mengingatnya peningkatan partisipasi seorang didalam dunia kerja. Berdasar kepada hasil penelitian itu bisa dibuat hipotes seperti berikut:

$\mathrm{H}_{1}$ : Work-Family Conflict memiliki pengaruh negatif terhadap Komitmen Organisasional

Riset Thomas Stefanus Kaihatu serta Wahju Astjarjo Rini (2007) memberikan petunjuk bahwasannya kepuasan kerja memiliki pengaruh yang signifikan pada komitmen organisasional. Hasil riset tersebut konsisten dengan penelitian Vandenberg dan Lance (1992); Knoop (1995) bahwasannya kepuasan akanlah kualitas kerja adalah aspek prediksi yang vital pada komitmen perusahaan didalam (Thomas Stefanus Kaihatu dan Wahju Astjarjo Rini, 2007). Oleh sebab itu, bila seorang sudah mendapatkan perasaan puas pada hasil kerja jadi mampu dibuat asumsi individual itu akanlah mempunyai komitmen yang besar pada kerjaannya. Sebaliknya, turunnya perasaan kepuasan didalam diri seorang pada kerjaannya akanlah membuat penurunan tertariknya individual dengan kerjaannya.

Clugston (2000), didalam penelitian terdahulu juga memberikan petunjuk bahwasannya ada hubungan yang positive diantara kepuasan kerja dengan komitmen pegawai. Kepuasan kerja yang besar akanlah memberikan pengaruh kejadian komitmen karyawan yang efektive. Hasil tersebut diperkuat oleh penelitian Azeem, (2010) pada 128 pegawai perusahaan industri Oman yang terpilih dengan acak memberikan petunjuk hubungan positive diantara kepuasan kerja dengan komitmen organisasi, para pegawai yang merasa puas pada upah serta promosi yang didapatkan akanlah memberikan peningkatan komitmen organisasi didalam diri pegawai. Sama seperti dua penelitian terdahulu riset yang dilaksanakan Tania dan Sutanto (2013) menghasilkan bahwasannya memberikan motivasi untuk pegawai mampu memberikan peningkatan kepuasan kerja serta memberikan kekuatan komitmen organisasi untuk diri pegawai. Berdasar kepada hasil penelitian itu mampu dituliskan hipotesa seperti berikut:

$\mathrm{H}_{2}$ : Kepuasan Kerja memiliki pengaruh positif dan signifikan terhadap Komitmen Organisasional

\section{METODE PENELITIAN}

Pendekatan yang dipakai dalam menyelesaikan masalah di riset berikut yaitu pendekatan kuantitatif yang mempunyai bentuk asosiatif, dikarenakan penelitian berikut mempunyai tujuan agar mendapatkan hubungan diantara dua variable ataupun lebih. Didalam penelitian berikut terkaji pengaruh variable work family conflict serta kepuasan kerja pada komitmen organisasional. Lokasi penelitian berikut adalah pada PT. Pasific Express Garment Denpasar Jalan Suwung Batan Kendal no.30, Sesetan, Denpasar. Lokasi ini dipilih karena perlu dianalisis mengenai work family conflict, kepuasan kerja dan komitmen organisasional pada PT. Pasific Express Garment Denpasar.

Subjek penelitian yang digunakan dalam penelitian kali ini adalah karyawan PT. Pasific Express Garment Denpasar. Obyek yang dilakukan penelitian didalam riset berikut yaitu work family conflict, kepuasan kerja, komitmen organisasional pada PT. Pasific Express Garment Denpasar. Dalam penelitian ini yang menjadi 
variabel dependen adalah komitmen organisasional (Y). Dalam penelitian ini yang menjadi variabel independen yaitu work family conflict $\left(\mathrm{X}_{1}\right)$ dan kepuasan kerja $\left(\mathrm{X}_{2}\right)$.

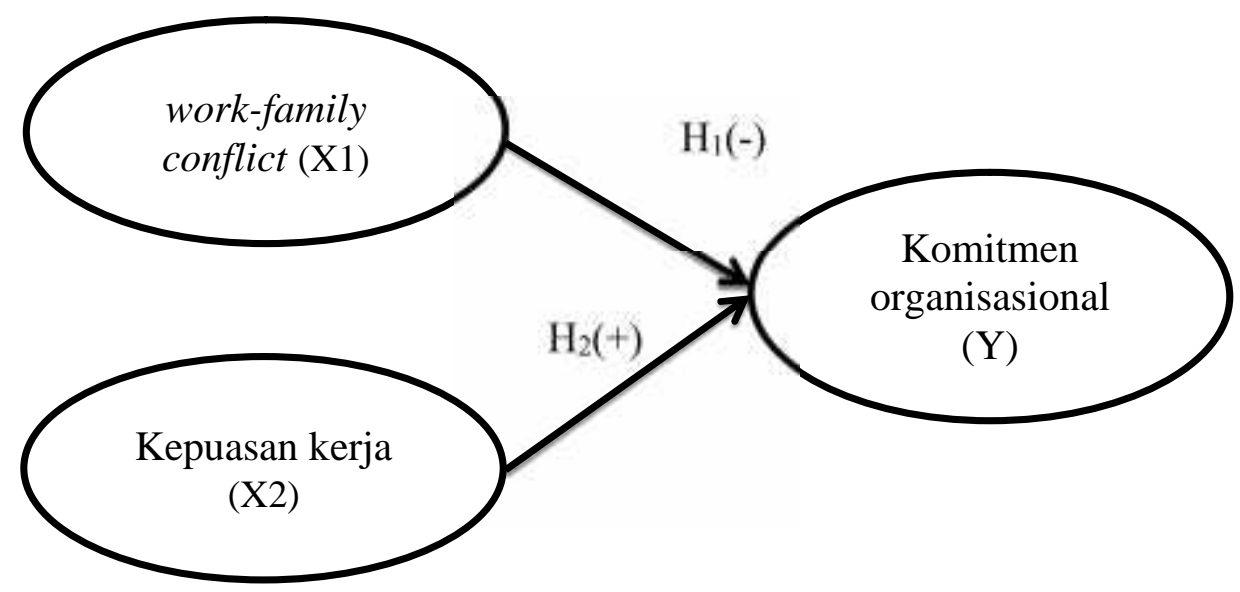

\section{Gambar 1. Kerangka Konseptual}

Sumber: Data diolah, 2019

Komitmen organisasional (Y) bisa dibilang sebagai ikatan psikologis pegawai pada perusahaannya ditunjukkan dengan kesetiaannya pada perusahaan, internalisasi tujuan perusahaan serta dedikasi dirinya untuk tujuan perusahaan. Menurut Allen dan Meyer (1997) terdapat tiga indikator yang mempengaruhi komitmen organisasional yaitu: Affective commitment $\left(\mathrm{Y}_{1.1}\right)$ adalah ungkapan sebagai perasaan emosional untuk organisasi dan keyakinan dalam nilai-nilai organisasi. Continuance commitment $\left(\mathrm{Y}_{1.2}\right)$ yaitu komitmen yang terbentuk atas dasar untung tugi yang dipetimbangkanuntuk menetap pada organisasi dibandingkan dengan meninggalkan organisasi tersebut. Normative commitment ( $\left.\mathrm{Y}_{1.3}\right)$ merupakan komitmen yang didasarkan atas peraturan, etika dan norma dalam diri karyawan yang didasari pada keyakinan individu pada tanggung jawab terhadap organisasi.

Work family conflict yaitu sebuah bentuk konflik peran yang dinyatakan bagai muncul tidaknya stimulus daripada dua sisi tekanan peran yang mana salah satunya peran dapat timbul suatu kesulitan serta rasa bimbang didalam pemenuhan tuntutan peran yang lain, hingga sangatlah mempunyai dampak untuk individualnya mampu terlihat daripada dampak sulitnya agar pembagian waktu serta sulitnya agar terlaksananya suatu peran dikarenakan ada tidaknya peran yang lainnya. Indikator dalam pengukuran work-family conflict yang teradopsi daripada instrumen yang berkembang oleh Greenhaus dan Beutell (1985) yang digunakan acuan Adekola (2010) jadi tiga macam work-family conflict, adalah: Time-based conflict $\left(\mathrm{X}_{1.1}\right)$ merupakan konflik yang ada dikarenakan waktu yang diperlukan agar mengoperasikan suatu tuntutan (keluarga ataupun pekerjaan) mampu melakukan pengurangan waktu dalam berjalannya tuntutan yang lain. Strainbased conflict $\left(\mathrm{X}_{1.2}\right)$ adalah konflik yang ada disaat tekanan daripada suatu peran memberikan pengaruh kinerja peran lain. Behavior-based conflict $\left(\mathrm{X}_{1.3}\right)$ 
merupakan konflik yang ada hubungan dengan tidak sesuainya diantara pola prilaku denganyang diingin oleh dua peran (pekerjaan ataupun keluarga).

Kepuasan kerja $\left(\mathrm{X}_{2}\right)$ adalah penilaian serta sikap seorang ataupun pegawai pada kerjaannya serta hubungan dengan lingkungan pekerjaan, jenis kerja, hubungan antara teman kerja, serta hubungan sosial pada tempat pekerjaan. Berdasar kepada pengertian itu indikator dalam pengukuran kepuasan kerja yang teradopsi daripada instrument yang berkembang oleh Boles et al., (2007) mencakup: Penilaian serta sikap pada beban pekerjaan, adalah kumpulan ataupun jumlah kegiatan yang harusnya terselesaikan oleh pegawai. Penilaian serta sikap pada upah, adalah pemberian reward berdasark hasil kerja pegawai. Penilaian serta sikap pada kenaikan jabatan, adalah kesempatan untuk pegawai agar selalu maju serta melakukan perkembangan bagai bentuk aktual diri. Penilaian serta sikap pada pengawasan, adalah mampu atau tidaknya atasannya agar memberikan perhatian juga memberi bantuan disaat pegawai mendapat sulitnya pekerjaan. Penilaian serta sikap pada rekan pekerjaan, adalah sampai mana pegawai bisa menunjukkan sikap persahabatan serta salingnya adanya dukungan didalam lingkungan pekerjaan.

Data kuantitatif didalam riset berikut yaitu banyaknya pegawai dan penilaian jumlahnya kuesioner yang sudah dilakukan pentabulasian dengan sistem bobot jawaban responden yang berasal daripada work family conflict, kepuasan kerja serta komitmen organisasional. Data kualitatif didalam riset berikut yaitu wawancara, hasil observasi serta sejarah PT. Pasific Express Garment Denpasar. Data primer yang dikumpulkan dalam penelitian ini seperti data yang didapatkan dengan observasi langsung dan kuesioner yang disebarkan kepada responden. Istijanto (2010:33) sumber sekunder mampu terdefinisi bagai data yang sudah terkumpulkan pihak lainnya, tidak oleh peneliti sendiri, agar tujuan lainnya, misalnya jumlah pegawai, sejarah perusahaan, struktur perusahaan juga tingkat absensi karyawan.

Peneliti mengambil populasi penelitian pada seluruh karyawan produksi PT. Pasific Express Garment Denpasar karena mayoritas terjadinya penurunan komitmen organisasional terdapat pada karyawan produksi dengan jumlah karyawan sebanyak 45 orang. Sample yang terpilih didalam penelitian berikut memakai tehnik sampling jenuh yang dimana tehnik mendefinisikan sample apabila seluruh anggota populasi dipakai menjadi sample (Sugiyono, 2014:116). Berdasar kepada pengertian itu jadi responden didalam riset berikut yaitu 45 pegawai bagian produksi PT Pasific Express Garment Denpasar. Metode pengambilan data yang digunakan adalah Observasi, Wawancara dan Kuesioner.

Teknik analisis yang digunakan pada penelitian ini adalah Analisis Regresi Linear Berganda yang sebelumnya dilakukan uji asumsi klasik terlebih dahulu. Analisis regresi linear berganda ini digunakan untuk tujuan penelitian yaitu menganalisis pengaruh work family conflict serta kepuasan kerja pada komitmen organisasional pegawai. Dimana variabel bebasnya adalah work family conflict dan kepuasan kerja, sedangkan variabel terikatnya adalah komitmen organisasional. Persamaan regresi linier berganda dirumuskan secara matematis seperti berikut (Nata Wirawan, 2002). 


$$
Y=\alpha+\beta_{1} X_{1}+\beta_{2} X_{2}+\varepsilon
$$

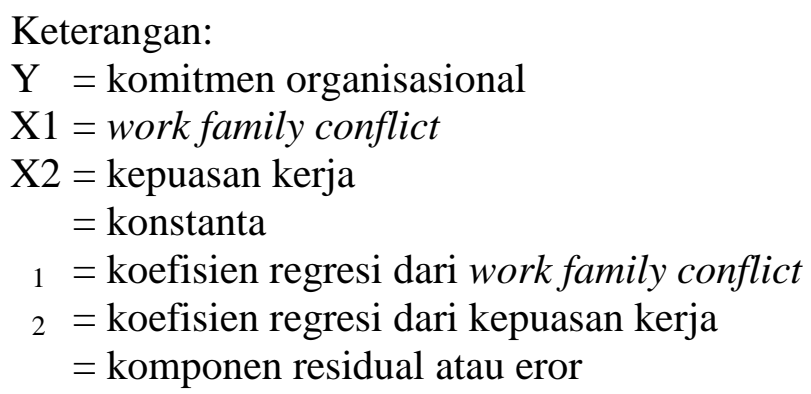

Pengujian hipotesis dalam penelitian ini dapat dilakukan, apabila model regresi linier berganda sudah memenuhi syarat uji asumsi klasik. Uji asumsi klasik terdiri dari empat bagian yaitu; uji normalitas, uji heteroskedastisitas, uji autokorelasi, dan uji multikolinieritas. Namun penelitian ini tidak menggunakan uji autokorelasi dikarenakan data penelitian ini dalam bentuk data cross section (Sugiyono, 2014).

Uji normalitas bertujuan untuk menguji apakah dalam residual dari model regresi yang di buat berdistribusi normal atau tidak. Untuk menguji normalitas data, digunakan uji Kolmogorov-Smirnov (KS-Test) dengan cara melihat angka protabilitas signifikan dari variable work family conflict, kepuasan kerja dan komitmen organisasional dimana data dapat dikatakan normal apabila angka signifikansinya lebih besar dari 0,05 (Surbakti, 2013).

Uji multikolinearitas bertujuan untuk menguji apakah ada model regresi ditemukan adanya kolerasi antara variabel bebas. Uji Glejser dengan bantuan SPSS digunakan dalam mendeteksi adanya heterokedastisitas dengan cara meregresi nilai absolut residual terhadap variabel independen yang terdiri atas work family conflict dan kepuasan kerja. Apabila nilai signifikansi yang dihasilkan lebih dari 0,05 maka tidak terjadi gejala heterokedastisitas (Surbakti, 2013).

Uji heteroskedastisitas bertujuan menguji apakah dalam model regresi terjadi ketidaksamaan varians dari residual satu pengamatan ke pengamatan lain. Uji multikolinieritas dilakukan dengan melakukan uji kolerasi variabel independen yang terdiri atas work family conflict dan kepuasan kerja. Uji ini dilakukan dengan menggunakan bantuan SPSS for Windows dengan cara melihat apabila niai VIF dibawah 10 maka tidak terdapat masalah multikolinieritas (Surbakti, 2013).

Uji kelayakan model (uji F) bertujuan untuk mengetahui kelayakan model regresi Iinier berganda sebagai alat analisis yang menguji pengaruh variabel independen terhadap variabel dependen secara bersama. Apabila tingkat signifikan lebih dari $\alpha=0,05$ maka regresi ini layak untuk digunakan sebagai alat analisis (Ghozali, 2011: 98). Uji ini digunakan untuk menguji signifikan masingmasing koefisien regresi berganda $(\mathrm{R})$, sehingga diketahui apakah secara parsial pengaruh antara work family conflict dan kepuasan kerja terhadap komitmen organisasional adalah memang nyata terjadi (signifikan) atau hanya diperoleh secara kebetulan. 


\section{HASIL DAN PEMBAHASAN}

Responden penelitian digambarkan secara umum dengan menyajikan profilnya dilihat dari beberapa variabel demografi yaitu jenis kelamin laki-laki sejumlah 13 orang sedangkan perempuan berjumlah 32 responden dengan persentase masing-masing 29 persen dan 71 persen ini menunjukkan PT. Pacific Express Garment membutuhkan tenaga kerja yang membuthkan ketelitian dan perempuan dinilai lebih teliti dan terampil.

Tabel 2.

Hasil Uii Validitas

\begin{tabular}{cccc}
\hline Variabel & Instrumen & Pearson Correlation & Keterangan \\
\hline Work-Family Conflict & X1.1 & 0,892 & Valid \\
(X1) & X1.2 & 0,907 & Valid \\
Kepuasan Kerja & X1.3 & 0,909 & Valid \\
(X2) & X2.1 & 0,717 & Valid \\
& X2.2 & 0,768 & Valid \\
& X2.3 & 0,862 & Valid \\
Komitmen Organisasional & X2.4 & 0,882 & Valid \\
(Y) & X2.5 & 0,769 & Valid \\
& Y.1 & 0,792 & Valid \\
& Y.3 & 0,839 & Valid \\
& Y.4 & 0,878 & Valid \\
& Y.5 & 0,755 & Valid \\
& Y.6 & 0,813 & Valid \\
& Y.7 & 0,856 & Valid \\
& Y.8 & 0,878 & Valid \\
& Y.9 & 0,861 & Valid
\end{tabular}

Sumber : Data diolah, 2019

Menurut segi usia, responden yang mendominasi pengisian kuesioner penelitian adalah yang memiliki usia $<30$ tahun sebanyak 16 orang dengan persentase 36 persen dimana tenaga kerja dengan usia tersebut sedang dalam pucak produktivitasnya sehingga mampu focus di pekerjaannya serta dari pendidikan didominasi oleh responden dengan pendidikan terakhir SMA dengan jumlah sebanyak 17 orang dengan persentase sebanyak 38 persen yang menunjukkan perusahaan tidak terlalu membutuhkan pekerja yang sudah menempuh pendidikan tinggi seperti diploma ataupun sarjana. Hasil uji validitas instrumen penelitian Tabel 2. memberikan petunjuk bahwasannya semua indikator didalam variable work-family conflict, kepuasan kerja serta komitmen organisasional mempunyai nilai Pearson Correlation yang lebih tinggi daripada angka 0,30 hingga semua indikator itu dinyatakan sudah terpenuhinya syarat validitas data. Instrumen dikatakan reliabel untuk mengukur variabel bila berada di atas angka 0,60. Hasil pengujian reliabilitas instrumen dapat dilihat pada Tabel 3. 
Tabel 3.

Hasil Uji Reliabilitas

\begin{tabular}{ccc}
\hline Variabel & Cronbadh'sAlpha & Keterangan \\
\hline Work-Family Conflict & 0,886 & Reliabel \\
Kepuasan Kerja & 0,857 & Reliabel \\
Komitmen Organisasional & 0,777 & Reliabel \\
\hline Sumber $:$ Data diolah, 2019 & &
\end{tabular}

Berdasarkan Tabel 3. dapat dilihat bahwa ketiga variabel penelitian yaitu work-family conflict, kepuasan kerja serta komitmen organisasional mempunyai koefisien cronbach's alpha yang lebih tinggi daripada angka 0,60 hingga bisa dinyatakan reliabel. Distribusi penilaian responden, mengenai work-family conflict $\left(\mathrm{X}_{1}\right)$ dapat dilihat pada Tabel 4. sebagai berikut.

Tabel 4.

Hasil Penilaian Responden atas Variabel Work-Family Conflict

\begin{tabular}{|c|c|c|c|c|c|c|c|c|}
\hline \multirow{2}{*}{ No } & \multirow{2}{*}{ Pernyataan } & \multicolumn{5}{|c|}{ Jawaban } & \multirow{2}{*}{$\begin{array}{l}\text { Rata- } \\
\text { rata } \\
\text { Skor }\end{array}$} & \multirow{2}{*}{$\begin{array}{l}\text { Kategori } \\
\text { Penilaian }\end{array}$} \\
\hline & & STS & TS & $\mathbf{N}$ & $\mathbf{S}$ & SS & & \\
\hline 1 & $\begin{array}{l}\text { Saya merasa kesulitan untuk } \\
\text { mengatur waktu antara pekerjaan } \\
\text { dengan keluarga. }\left(\mathrm{X}_{1.1}\right)\end{array}$ & 0 & 10 & 13 & 17 & 5 & 3,38 & Cukup \\
\hline 2 & $\begin{array}{l}\text { Saya merasa beban kerja yang } \\
\text { diberikan organisasi mengganggu } \\
\text { waktu berkumpul dengan keluarga. } \\
\left(\mathrm{X}_{1.2}\right)\end{array}$ & 0 & 7 & 11 & 15 & 12 & 3,71 & Tinggi \\
\hline 3 & $\begin{array}{llr}\text { Pekerjaan kantor sering saya } \\
\text { kerjakan di rumah } & \text { sehingga } \\
\text { mengganggu } & \text { waktu } & \text { senggang } \\
\text { bersama keluarga. }\left(\mathrm{X}_{1.3}\right)\end{array}$ & 0 & 13 & 12 & 16 & 4 & 3,24 & Cukup \\
\hline \multicolumn{2}{|c|}{ Variabel work-family conflict } & & & & & & 3,44 & Tinggi \\
\hline
\end{tabular}

Tabel 4. memberikan penjelasan persepsi responden tentang variable workfamily conflict bisa terlihat dengan keseluruhannya mempunyai nilai jumlah ratarata skor variabel sejumlah 3,44 yang masuk didalam kategori tinggi. Terdapat dua indikator yang memiliki rata-rata skor dibawah rata-rata skor variabel adalah indikator $\mathrm{X}_{1.1}$ dengan rata-rata skor 3,38 dan pernyataan $\mathrm{X}_{1.3}$ dengan rata-rata skor 3,24 . Kedua indikator yang dibawah rata-rata tersebut adalah indikator time-based conflict dimana responden tidak merasa kesulitan membagi waktu antara keluarga dan pekerjaan serta behavior-based conflict dimana responden tidak merasa ada banyak pekerjaan yang masih harus dikerjakan diluar jam kantor sehingga 
mengganggu waktu yang seharusnya untuk keluarga. Sedangkan indikator yang memiliki rata-rata skor diatas rata-rata skor variabel adalah indikator $\mathrm{X}_{1.2}$ yang rata-rata skornya adalah 3,71 masuk dalam kategori tinggi, dimana indikator ini adalah strain-based conflict dimana responden merasakan beban kerjanya terlalu berat sehingga membuat waktu berkumpul bersama keluarga tidak maksimal karena sudah merasakan kelelahan saat bekerja.

Tabel 5.

\section{Hasil Penilaian Responden atas Variabel Kepuasan Kerja}

\begin{tabular}{|c|c|c|c|c|c|c|c|c|}
\hline \multirow{2}{*}{ No } & \multirow{2}{*}{ Pernyataan } & \multicolumn{5}{|c|}{ Jawaban } & \multirow{2}{*}{$\begin{array}{l}\text { Rata- } \\
\text { rata } \\
\text { Skor }\end{array}$} & \multirow{2}{*}{$\begin{array}{l}\text { Kategori } \\
\text { Penilaian }\end{array}$} \\
\hline & & STS & TS & $\mathbf{N}$ & $\mathbf{S}$ & SS & & \\
\hline 1 & $\begin{array}{l}\text { Pekerjaaan saya sekarang ini sesuai } \\
\text { dengan keahlian saya }\left(\mathrm{X}_{2.1}\right)\end{array}$ & 0 & 3 & 8 & 21 & 13 & 3,98 & Tinggi \\
\hline 2 & $\begin{array}{l}\text { Besarnya gaji yang diterima sudah } \\
\text { sesuai dengan pekerjaan yang } \\
\text { dibebankan oleh organisasi }\left(X_{2.2}\right)\end{array}$ & 1 & 9 & 10 & 21 & 4 & 3,40 & Cukup \\
\hline 3 & $\begin{array}{lrr}\text { Saya } & \text { puas dengan } & \text { kesempatan } \\
\text { untuk } & \text { memperoleh } & \text { promosi } \\
\text { kenaikan jabatan }\left(\mathrm{X}_{2.3}\right) & \end{array}$ & 0 & 2 & 12 & 14 & 17 & 4,02 & Tinggi \\
\hline 4 & $\begin{array}{l}\text { Manajer selalu bersikap adil } \\
\text { terhadap karyawannya }\left(\mathrm{X}_{2.4}\right)\end{array}$ & 0 & 4 & 13 & 20 & 8 & 3,71 & Tinggi \\
\hline 5 & $\begin{array}{l}\text { Hubungan kerja sama dengan rekan } \\
\text { kerja di tempat kerja sudah terjalin } \\
\text { dengan baik }\left(\mathrm{X}_{2.5}\right)\end{array}$ & 0 & 2 & 10 & 24 & 9 & 3,89 & Tinggi \\
\hline Var & abel Kepuasan Kerja & & & & & & $\mathbf{3 , 8 0}$ & Tinggi \\
\hline
\end{tabular}

Tabel 5. memberikan penjelasan persepsi responden tentang variable Kepuasan Kerja mampu terlihat dengan seluruhnya mempunyai nilai total ratarata skor variabel sejumlah 3,80 yang masuk didalam kategori tinggi. Terdapat tiga buah indikator yang memiliki rata-rata skor diatas rata-rata skor variabel adalah indikator $\mathrm{X}_{2.1} ; \mathrm{X}_{2.3} ; \mathrm{X}_{2.5}$ yang masing-masing memiliki rata-rata skor 3,98; 4,02 dan 3,89, dimana indikator ini menyatakan bahwa responden merasa puas dengan pekerjaannya saat ini karena sesuai dengan keahliannya, adanya kesempatan mendapatkan promosi dalam pekerjaannya dan hubungan dengan sesama rekan kerja yang baik. Sedangkan pernyataan yang memiliki rata-rata skor dibawah rata-rata skor variabel ada dua indikator yaitu indikator $\mathrm{X}_{2.2}$ dengan ratarata skor 3,40 serta indikator $\mathrm{X}_{2.4}$ dengan rata-rata skor 3,71 dimana hasil tersebut berarti responden merasa kurang puas dengan pekerjaannya sekarang karena gaji yang diterima belum sesuai dengan beban kerja yang ditanggung dan responden menilai atasan masih belum bersikap adil pada seluruh karyawan.

Tabel 6. memberikan penjelasan persepsi responden tentang variable Komitmen Organisasional bisa terlihat dengan seluruhnya mempunyai nilai total rata-rata jawaban responden sejumlah 3,79 yang masuk didalam kategori tinggi. 
Terdapat lima indikator yang memiliki rata-rata skor diatas rata-rata skor variabel kedelapan adalah indikator $\mathrm{Y}_{1.1 .3} ; \mathrm{Y}_{1.2 .1} ; \mathrm{Y}_{1.3 .1} ; \mathrm{Y}_{1.3 .2} ; \mathrm{Y}_{1.3 .3}$ dimana ini berarti responden memiliki Normative Commitment $\left(\mathrm{Y}_{1.3}\right)$ yang artinya responden komitmen yang didasarkan atas peraturan, etika dan norma dalam diri karyawan yang didasari pada keyakinan individu pada tanggung jawab terhadap organisasi. Responden juga mempunyai satu indikator Affective commitment ( $\left.\mathrm{Y}_{1.1}\right)$ yang diatas rata-rata serta satu indikator Continuance commitment $\left(\mathrm{Y}_{1.2}\right)$ yang diatas rata-rata yaitu perasaan dalam menjadi bagian dari organisasi ( $\left.\mathrm{Y}_{1.1 .3}\right)$ dan terganggunya kehidupan karyawan apabila meninggalkan organisasi ( $\left.\mathrm{Y}_{1.2 .1}\right)$.

Tabel 6.

Hasil Penilaian Responden atas Variabel Komitmen Organisasional

\begin{tabular}{|c|c|c|c|c|c|c|c|c|}
\hline \multirow{2}{*}{ No } & \multirow{2}{*}{ Pernyataan } & \multicolumn{5}{|c|}{ Jawaban } & \multirow{2}{*}{$\begin{array}{l}\text { Rata- } \\
\text { rata } \\
\text { Skor }\end{array}$} & \multirow{2}{*}{$\begin{array}{l}\text { Kategori } \\
\text { Penilaian }\end{array}$} \\
\hline & & STS & TS & $\mathbf{N}$ & $\mathbf{S}$ & SS & & \\
\hline 1 & $\begin{array}{l}\text { Saya senang menghabiskan waktu } \\
\text { kerja saya pada organisasi ini . } \\
\left(\mathrm{Y}_{1.1 .1}\right)\end{array}$ & 0 & 4 & 13 & 24 & 4 & 3,62 & Tinggi \\
\hline 2 & $\begin{array}{l}\text { Organisasi ini sangat berarti bagi } \\
\text { kehidupan saya }\left(\mathrm{Y}_{1.1 .2}\right)\end{array}$ & 0 & 4 & 17 & 15 & 9 & 3,64 & Tinggi \\
\hline 3 & $\begin{array}{l}\text { Saya bangga menjadi bagian dari } \\
\text { organisai ini }\left(\mathrm{Y}_{1.1 .3}\right)\end{array}$ & 0 & 2 & 16 & 15 & 12 & 3,82 & Tinggi \\
\hline 4 & $\begin{array}{l}\text { Kehidupan saya akan sangat } \\
\text { terganggu bila meninggalkan } \\
\text { organisasi ini sekarang. }\left(\mathrm{Y}_{1.2 .1}\right)\end{array}$ & 0 & 1 & 15 & 21 & 8 & 3,80 & Tinggi \\
\hline 5 & $\begin{array}{l}\text { Sulit mendapatkan pekerjaan } \\
\text { dengan penghasilan yang bagus } \\
\text { seperti pekerjaan saya sekarang. } \\
\left(\mathrm{Y}_{1.2 .2}\right)\end{array}$ & 0 & 5 & 10 & 20 & 10 & 3,78 & Tinggi \\
\hline 6 & $\begin{array}{l}\text { Saya akan merasa sangat rugi jika } \\
\text { keluar dari organisasi ini. }\left(\mathrm{Y}_{1.2 .3}\right)\end{array}$ & 0 & 5 & 15 & 17 & 8 & 3,62 & Tinggi \\
\hline 7 & $\begin{array}{lcc}\text { Saya bersedia terlibat } & \text { dalam } \\
\text { setiap kegiatan kerja } & \text { dalam } \\
\text { organisasi }\left(\mathrm{Y}_{1.3 .1}\right) & & \end{array}$ & 0 & 4 & 5 & 24 & 12 & 3,98 & Tinggi \\
\hline 8 & $\begin{array}{l}\text { Organisasi ini layak mendapatkan } \\
\text { kesetian dari saya. }\left(\mathrm{Y}_{1.3 .2}\right)\end{array}$ & 0 & 1 & 9 & 24 & 11 & 4,00 & Tinggi \\
\hline 9 & $\begin{array}{l}\text { Saya merasa, bekerja dalam } \\
\text { organisasi ini adalah suatu } \\
\text { kewajiban }\left(\mathrm{Y}_{1.3 .3}\right)\end{array}$ & 0 & 2 & 12 & 21 & 10 & 3,87 & Tinggi \\
\hline Var & abel Komitmen Organisasional & & & & & & 3,79 & Tinggi \\
\hline
\end{tabular}

Sumber: Data diolah, 2019

Uji normalitas memiliki tujuan agar pengujian apa didalam model regresi, variable penggangu ataupun residual mempunyai distribusi normal ataupun tidaknya. Agar terhindar terjadi bias, data yang dipakai harusnya memiliki distribusi dengan normal. Model regresi yang bagus yaitu mempunyai data normal 
ataupun mendekati normal. Pengujian residual menggunakan uji KolmogorovSmirnov. Residual berdistribusi normal apabila tingkat signifikasinya menunjukkan nilai lebih besar 0,05 .

Tabel 7.

Hasil Uji Normalitas

\begin{tabular}{lc}
\hline & Unstandardized Residual \\
\hline $\mathbf{N}$ & 45 \\
Kolmogorov-Smirnov Z & 0,925 \\
Asymp.Sig.(2-tailed) & 0,360 \\
\hline
\end{tabular}

Sumber : Data diolah, 2019

Berdasar kepada Tabel 7. bisa terlihat bahwasannya nilai Kolmogorov Sminarnov (K-S) sejumlah 0,925, sedang nilai Asymp. Sig. (2-tailed) sejumlah 0,360. Hasil itu memberikan indikasi bahwasannya model persamaan regresi itu memiliki distribusi normal dikarenakan nilai Asymp. Sig. (2-tailed) 0,360 lebih tinggi daripada nilai alpha 0,05 .

Uji multikolinearitas dilaksanakan agar terlihat apa ada korelasi yang sempurna diantara variable independen yang dipakai di riset berikut. Menurut Ghozali (2010), menguji dilaksanakan lewat, nilai tolerance serta nilai VIF (Variance Inflation Factor). Bila nilai tolerance melebihi $10 \%$ ataupun VIF Kurang dari 10, jadi dikatakan tidak ada multikolinearitas.

Tabel 8.

Hasil Uji Multikolinearitas

\begin{tabular}{lccc}
\hline Variabel & Tolerance & \multicolumn{2}{c}{ VIF } \\
\hline Work-Family Conflict $\left(\mathrm{X}_{1}\right)$ & 0,802 & 1,248 \\
Kepuasan Kerja $\left(\mathrm{X}_{2}\right)$ & 0,802 & 1,248 \\
\hline Sumber : Data diolah, 2019 & &
\end{tabular}

Berdasar kepada Tabel 8. bisa terlihat bahwasannya nilai tolerance serta VIF daripada variable work-family conflict dan kepuasan kerja memberi petunjuk nilai tolerance melebihi daripada $10 \%$ serta nilai VIF lebih kecil daripada 10 yang memiliki arti model persamaan regresi bebas daripada multikolinearitas.

Dalam penelitian ini untuk mendeteksi heteroskedastisitas data dapat dilakukan dengan cara Uji Glejser. Glejser mengusulkan untuk meregres nilai absolut residual terhadap variabel independen. Dengan tingkat signifikasi 5\% maka model terbebas atau tidaknya dari masalah Heteroskedastisitas : Jika probabilitas $\mathrm{P}>0,05$ model terbebas dari masalah Heteroskedastisitas, jika probabilitas $\mathrm{P}<0,05$ model tidak terbebas dari masalah Heteroskedastisitas.

Tabel 9.

Hasil Uji Heteroskedastisitas

\begin{tabular}{lc}
\hline Variabel & Sig \\
\hline Work-Family Conflict $\left(\mathrm{X}_{1}\right)$ & 0,180 \\
Kepuasan Kerja $\left(\mathrm{X}_{2}\right)$ & 0,065 \\
\hline
\end{tabular}

Sumber : Data diolah, 2019 
Pada Tabel 9. dapat dilihat bahwa nilai Sig. dari variabel Work-Family Conflict sebesar 0,180, dan variabel Kepuasan Kerja sebesar 0,065. Hasil tersebut menunjukkan bahwa seluruh variabel terbebas dari masalah heteroskedastisitas karena nilai Sig. > 0,05. Pengujian data didalam penelitian berikut memakai tehnik analisis regresi linier berganda. Penghitungan koefisien regresi linier berganda dilaksanakan dengan analisis regresi lewat software SPSS 22.0 for Windows, didapatkan hasil yang ditampilkan di Tabel berikut:

Tabel 10.

Hasil Analisis Regresi Berganda

\begin{tabular}{lrrr}
\hline \multicolumn{1}{c}{ Variabel } & Nilai Koefisien Regresi & t hitung & Nilai Signifikansi \\
& & & \\
\hline Konstanta & 1,582 & 3,583 & 0,001 \\
Work-Family Conflict $\left(\mathrm{X}_{1}\right)$ & $-0,131$ & $-2,124$ & 0,040 \\
Kepuasan Kerja $\left(\mathrm{X}_{2}\right)$ & 0,701 & 8,856 & 0,000 \\
\hline R Square & & & $\mathbf{0 , 7 4 8}$ \\
Adjusted R Square & & & $\mathbf{0 , 7 3 6}$ \\
F Statistik & & $\mathbf{6 2 , 1 9 3}$ \\
Signifikansi & & $\mathbf{0 , 0 0 0}$ \\
\hline Sumb: Dan
\end{tabular}

Sumber: Data diolah, 2019

Berdasar kepada hasil analisis regresi linier berganda yang tersaji di Tabel 10, jadi didapat nilai koefisien regresi untuk masing-masing variabel adalah 0,131 untuk variabel work-family conflict $\left(\mathrm{X}_{1}\right)$, dan 0,701 untuk variabel kepuasan kerja $\left(\mathrm{X}_{2}\right)$ sehingga dapat dituliskan model persamaan regresinya sebagai berikut:

$$
\mathrm{Y}=1,582-0,131 \mathrm{X}_{1}+0,701 \mathrm{X}_{2}+\mathrm{e}
$$

Persamaan regresi diatas menunjukkan nilai konstanta sebesar 1,582 yang berarti apabila $\mathrm{X}_{1}$ dan $\mathrm{X}_{2}$ sama dengan 0 maka nilai $\mathrm{Y}$ adalah sebesar nilai konstanta yaitu 1,582. Nilai - 0,131 adalah nilai koefisien regresi untuk variabel work-family conflict yang artinya work-family conflict memiliki pengaruh negatif pada komitmen organisasional jadi, bila work-family conflict meningkat maka komitmen organisasional akan menurun, begitu pula sebaliknya, bila work-family conflict menurun maka komitmen organisasional akan meningkat.

Nilai 0,701 adalah nilai koefisien regresi untuk variabel kepuasan kerja yang artinya kepuasan kerja memiliki pengaruh positif terhadap komitmen organisasional, jadi apabila kepuasan kerja meningkat maka komitmen organisasional akan meningkat, begitu pula sebaliknya apabila kepuasan kerja menurun maka komitmen organisasional akan menurun juga.

Berdasarkan hasil analisis regresi linier berganda seperti yang disajikan Tabel 10. didapat nilai determinasi total sejumlah 0,748 memiliki arti bahwasannya sejumlah 74,8 persen variasi komitmen organisasional terpengaruhi 
oleh variasi work-family conflict serta kepuasan kerja namun sisa sejumlah 25,2 persen diberikan penjelasan oleh factor-faktor lainnya yang tak masuk kedalam model seperti misalnya variabel loyalitas karyawan, kepemimpinan transformasional, iklim organisasi dan sistem reward.

Berdasarkan hasil uji kelayakan model, diperoleh nilai $\mathrm{F}$ sebesar 62,193 dengan tingkat signifikansi 0,000 lebih kecil dari 0,05, artinya model regresi yang digunakan telah memenuhi syarat uji kelayakan model atau Goodness of Fit pada Tabel 10 dapat dilihat bahwa pada model memiliki nilai signifikansi sebesar 0,000 lebih kecil dari nilai probabilitas 0,05 . Hal ini berarti bahwa secara bersama-sama (simultan) work-family conflict $\left(\mathrm{X}_{1}\right)$ dan kepuasan kerja $\left(\mathrm{X}_{2}\right)$ berpengaruh signifikan terhadap variabel terikat yaitu komitmen organisasional (Y).

Nilai $t$ sig sama dengan $0,040<0,05$ dan $\beta_{1}$ sama dengan $-0,131$ ini artinya ada pengaruh secara parsial work-family conflict terhadap komitmen organisasional. Nilai $\beta_{1}$ sama dengan $-0,131$ berarti work-family conflict mempunyai pengaruh yang negative pada komitmen organisasional pegawai di PT Pasific Express Garment Denpasar, dengan demikian hipotesis pertama diterima. Nilai $\mathrm{t}$ sig sama dengan $0,000<0,05$ dan $\beta_{2}$ sama dengan 0,701 maka $\mathrm{H}_{0}$ ditolak dan $\mathrm{H}_{1}$ diterima. Artinya ada pengaruh secara parsial kepuasan kerja Terhadap komitmen organisasional. Nilai $\beta_{2}$ sama dengan 0,701 berarti kepuasan kerja memiliki pengaruh yang positif terhadap komitmen organisasioal karyawan pada PT Pasific Express Garment Denpasar, dengan demikian hipotesis kedua diterima.

Work family conflict $\left(\mathrm{X}_{1}\right)$ merupakan sebuah bentuk konflik peran yang dinyatakan seperti muncul tidaknya stimulus daripada dua sisi tekanan peran yang mana salah satunya peran akanlah timbulnya rasa sulitnya serta rasa bimbang didalam pemenuhan penuntutan peran yang lain, hingga sangatlah memiliki dampak untuk individual mampu terlihat daripada dampak sulitnya agar pembagian waktu serta sulitnya agar melakukan satu diantara peran lainnya dikarenakan ada tidaknya peran lainnya. Berdasarkan hasil penelitian didapatkan bahwa work-family conflict mempunyai pengaruh yang negative pada komitmen organisasional pegawai di PT Pasific Express Garment Denpasar, dengan demikian hipotesis pertama diterima.

Hasil yang signifikan ini disebabkan oleh adanya kondisi karyawan merasa kesulitan membagi waktu antara keluarga dan pekerjaan. Selain itu responden merasa sering terganggunya waktu untuk bersama keluarga dikarenakan ada banyak pekerjaan yang masih harus dikerjakan diluar jam kantor. Hasil yang sama pula terungkap oleh Boles et al., (2001) yang mana work-family conflict mampu memberi penurunan prestasi kerja pegawai, turunnya prestasi kerja pegawai bisa memberikan efek di turunnya komitmen organisasi. Hasil berikut dikuatkan oleh Balmforth \& Gardner, (2006) memberikan petunjuk bahwasannya work-family conflict mempunyai hubungan negative dengan komitmen organisasional. Hubungan negative diantara work-family conflict serta komitmen organisasional terlihat di pegawai yang mendapatkan sulitnya didalam melakukan penyelarasan perannya pada keluarga ataupun dipekerjaan akanlah merasakan pengurangan komitmen pada perusahaannya.

Kepuasan kerja $\left(\mathrm{X}_{2}\right)$ adalah penilaian serta sikap seorang ataupun pegawai pada kerjaannya serta memiliki hubungan dengan lingkungan pekerjaan, jenis 
kerja, hubungan antara teman pekerjaan, serta hubungan sosial pada tempat pekerjaan. Berdasar kepada hasil penelitian didapatka bahwa kepuasan kerja memiliki pengaruh yang positif terhadap komitmen organisasioal karyawan pada PT Pasific Express Garment Denpasar, dengan demikian hipotesis kedua diterima.

Pengaruh yang signifikan pada hubungan ini disebabkan adanya persepsi puasnya karyawan terhadap pekerjaan mereka karena telah sesuai dengan keahlian mereka. Selain itu kesempatan promosi dan hubungan dengan sesama rekan kerja juga memberikan sumbangsih terhadap pengaruh yang signifikan antara kepuasan kerja terhadap komitmen organisasional. Penelitian terdahulu yang memperoleh hasil yang sama dilakukan Clugston, (2010), didalam penelitian terdahulu juga memberikan petunjuk bahwasannya ada hubungan yang positive diantara kepuasan kerja dengan komitmen pegawai. Kepuasan kerja yang besar akanlah memberikan pengaruh kejadian komitmen karyawan yang efektive. Hasil tersebut diperkuat oleh penelitian Azeem, (2010) pada 128 pegawai perusahaan industri Oman yang terpilih dengan acak memberikan petunjuk hubungan positive diantara kepuasan kerja dengan komitmen organisasi, para pegawai yang merasa puas pada upah serta promosi yang didapatkan akanlah memberikan peningkatan komitmen organisasi didalam diri pegawai. Sama seperti dua penelitian terdahulu riset yang dilaksanakan Tania dan Sutanto (2013) menghasilkan bahwasannya memberikan motivasi untuk pegawai mampu memberikan peningkatan kepuasan kerja serta memberikan kekuatan komitmen organisasi untuk diri pegawai.

Penelitian ini bisa memberikan informasi penting untuk PT. Pasific Express Garment Denpasar agar dapat menurunkan adanya work-family conflict di lingkungan perusahaan yang dapat dirasakan oleh karyawannya serta meningkatkan kepuasan kerja yang dirasakan karyawannya sehingga dapat meningkatkan komitmen organisasional oleh para karyawan PT. Pasific Express Garment Denpasar. Kepuasan kerja yang semakin tinggi yang dirasakan oleh para karyawan juga mampu meningkatkan komitmen organisasional yang dirasakan karyawannya. Dengan memperkecil adanya work-family conflict serta meningkatkan kepuasan kerja yang dirasakan karyawannya, diharapkan kedepannya PT. Pasific Express Garment Denpasar semakin mampu meningkatkan adanya komitmen organisasional para karyawannya. Penelitian berikut pula harapannya mampu memberi sumbangan pada ilmu khusus manajemen SDM, langsung menambah teori-teori work-family conflict, kepuasan kerja dan komitmen organisasional.

\section{SIMPULAN}

Hasil analisa serta pembahasan mengenai hubungan diantara variable riset memberi kesimpulan riset seperti ini. Variable work-family conflict mempunyai pengaruh negatif serta signifikan pada komitmen organisasional karyawan PT. Pasific Express Garment Denpasar. Hasil tersebut memperlihatkan bahwa semakin meningkatnya Work-Family Conflict pada karyawan PT. Pasific Express Garment Denpasar maka akan menurunkan komitmen organisasional yang dirasakan karyawan. Variabel Kepuasan Kerja berpengaruh positif terhadap Komitmen Organisasional karyawan PT. Pasific Express Garment Denpasar. Hal 
ini memiliki makna bahwa semakin puas karyawannya, maka akan semakin tinggi pula komitmen organisasional yang ditunjukkan oleh karyawan PT. Pasific Express Garment Denpasar.

Saran yang bisa disarankan berdasar kepada hasil analisa serta pembahasan yaitu seperti ini. Secara praktis saran yang dapat diberikan adalah pihak manajemen PT. Pasific Express Garment Denpasar haruslah lebih sering untuk memperhatikan beban kerja yang akan diberikan kepada karyawan sehingga beban kerja tidak akan mengganggu waktu karyawan bersama keluarga. Manajemen PT. Pasific Express Garment Denpasar harus lebih memperhatikan besarnya insentif yang akan diberikan kepada setiap karyawannya dengan memberikan insentif yang sesuai dengan beban kerja yang dilakukan karyawannya. Pihak pimpinan PT. Pasific Express Garment Denpasar harus lebih memperhatikan kenyamanan dari karyawannya sehingga karyawan dapat merasa senang serta merasa rugi apabila keluar dari perusahaan.

Secara teoritis berdasarkan hasil regresi ditemukan bahwa kepuasan kerja mempunyai pengaruh yang tinggi terhadap komitmen organisasional berdasarkan besaran koefisien beta dibandingkan dengan work-family conflict, sehingga disarankan untuk selanjutnya dapat meneliti lebih lanjut penelitian tentang kepuasan kerja pada komitmen organisasional. Bagi peneliti selanjutnya, ada harapan agar melaksanakan penelitian dengan pencakupan yang lebih luasnya, tambahan variable-variable lainnya diluar riset berikut seperti variabel kepemimpinan, sistem reward, loyalitas pegawai atau iklim organisasi juga diharap bisa tambahan referensi ataupun sumber yang lebih lagi pada variable yang akanlah dilakukan penelitian.

\section{REFERENSI}

Acha, V. (2013). THE RELATIONSHIP BETWEEN EMOTIONAL INTELLIGENCE OF A LEADER AND EMPLOYEE MOTIVATION TO JOB PERFORMANCE. Dissertation Presented in Partial Fulfillment Of the Requirements for the Degree Doctor of Philosophy, (September).

Adekola, Bola. 2010. Interferences between work and family among male and female executives in Nigeria. Journal of Business Management, 4(6):1069-1077.

Allen, Natalie J and Meyer, John P. 1990. The measurement and antecedents of affective, continuance and normative commitment to theorganization. Journal of Occupational Psychology, 63. pp: 1-18.

Allen, N.J., and Meyer, J.P. 1997. Three Component Conceptual Organizational of Organization Comitment. 1 Edition. Human Resoursce Management Review, 2(4), pp: 169-177.

Arikunto, Suharsini. 2002. Prosedur Penelitian, Suatu Pendekatan Praktis. Bina Aksara, Jakarta. 
Boles. J. S., W. G. Howard, and H. H. Donofrio. 2001. An Investigation into the Inter- Relationships of Work-Family Conflict, Family-Work Conflict and Work Satisfaction. Journal of Managerial Issues, 13 (2), pp: 376390.

Bushra, Fatima, Ahmad Usman, and Asvir Naveed. 2011. Effect of Transformational Leadership on Employees' Job Satisfaction and Organizational Commitment in Banking Sector of Lahore (Pakistan). International Journal of Business and Social Science, 2(18), pp: 261-267.

Hidayati, R., Purwanto, Y., \& Yuwono, S. (2011). Kecerdasan Emosi, Stres Kerja Dan Kinerja Karyawan. Jurnal Ilmiah Psikologi, 2(1), 91-96. Retrieved from https://ejournal.gunadarma.ac.id/index.php/psiko/article/view/249/190

Istijanto. 2010. Riset Sumber Daya Manusia. Jakarta : PT. Gramedia Pustaka Utama.

John, M.C. dan Taylor, J.W. 1999. Leadership Style, School Climate, and the Institutional Commitment of Teachers. International Forum Review, 2 (1), pp: 25-57.

Kopelman, R. E., Greenhaus J. H., Connoly T. F., 1983. A Model of Work Family Conflict: A Construct Validation Study.Organizational Behavior and Human Performance, 3(2), pp: 198

Lamba, Shruti, and Nirmala Choudary. 2013. Impact of HRM Practices on Organizational Commitment of Employees. International Journal of Advancements in Research \& Technology, 2(4), pp: 407-423

Nata, Wirawan. 2002. Cara Mudah Memahami Statistik 2 (Statistik Inferensial) Untuk Ekonomi dan Bisnis. Edisi Kedua. Denpasar: Keraras Emas.

Ngadiman., Anis Eliyana, and Dwi Ratmawati. 2013. Influence of Transformational Leadership and Organization Climate to the Work Satisfaction, Organizational Commitment and Organizational Citizenship Behavior on the Educational Personnel of Sebelas Maret University, Surakarta. European Journal of Business and Management, 5(10), pp: 97114.

Purnomo, Heru, dan Muhammad Cholil. 2010. Pengaruh Gaya Kepemimpinan Terhadap Kepuasan Kerja Berdasarkan Motivasi Kerja Pada Karyawan Administratif di Universitas Sebelas Maret Surakarta. Jurnal Manajemen Sumberdaya Manusia, 4(1), h: 27-35

Rehman, Rana Rashid.and Waheed, Ajmal. 2012.Work-Family Conflict and Organizational Commitment: Study of Faculty Members in PakistaniUniversities. Pakistan Journal of Social and Clinical Psychology, Vol. 10, No. 1, 23-26. 
Renny Rantika dan Sunjoyo, 2010. Pengaruh Konflik Kerja-keluarga terhadap Komitmen Organisasional yang Dimediasi oleh Kepuasan Kerja pada Profesi Perawat di Rumah Sakit Umum Daerah (RSUD) Dr. Moewardi Surakarta. Proceeding of Seminar Akbar Forum Manajemen Indonesia. 3(7), pp: 1-17

Riaz, Tabassum, Muhammad Umair Akram, and Hassan Ijaz. 2011. Impact of Transformational Leadership Style on Affective Employees' Commitment: an Empirical Study of Banking Sector in Islamabad (Pakistan). The Journal of Commerce, 3(1), pp: 43-51

Rivai, Veithzal dan Sagala, Ella Jauvani. 2011. Manajemen Sumber Daya Manusia untuk Perusahaan dari Teori ke Praktik. Jakarta: PT Rajagrafindo Persada.

Rizi, R. M., Aida Azadi, M. E. Farsani, and Shahram Aroufzad. 2013. Relationship between Leadership Styles and Job Satisfaction Among Physical Education Organizations Employees. European Journal of Sports and Exercise Science, 2(1), pp: 7-11

Robbins, S.P and Judge T. A. 2008. Perilaku Organisasi Organizational Behavior, Edisi 12. Salemba Empat.

Robbins, Stephen P. and Timothy A. Judge. 2009. Organizational Behaviour. Salemba Empat: Jakarta.

Senem Nart, Ozgur Batur, 2013. The relation between work-family conflict, job stress, organizational commitment and job performance: A study on turkish primary teachers. European Journal of Research on Education, 2(2), pp: $72-81$

Sugiyono. 2014. Metode Penelitian Pendekatan Kuantitatif, Kualitatif dan R\&D. Cetakan Pertama. Bandung: CV. Alfabeta.

Suhanto, Edi. 2009. Pengaruh Stres Kerja dan Iklim Organisasi Terhadap Turnover Intention dengan Kepuasan Kerja Sebagai Variabel Intervening. Tesis. Program Studi Magister Manajemen Universitas Diponegoro : p:21.

Surbakti. 2013. Analisis Pengaruh Kepemimpinan Transformasional dan Motivasi terhadap Kinerja Karyawan: Studi pada PT. Kereta Api Indonesia Daop IV Semarang. Jurnal Fakultas Ekonomi Universitas Diponegoro Semarang, I (1), 55-67.

Thomas Stefanus Kaihatu dan Wahju Astjarjo Rini, 2007, "Kepemimpinan Transformasional dan Pengaruhnya Terhadap Kepuasan Atas Kualitas Kehidupan Kerja, Komitmen Organisasi, dan Perilaku Ekstra Peran: Studi 
pada Guru-Guru SMU di Kota Surabaya", Jurnal Manajemen Dan Kewirausahan, Universitas Kristen Petra, Vol.98, No. 1, Maret 2007: p. 4961.

Thoyib, Armanu, Noermijati, dan Siska Kristin Sugianto. 2012. Pengaruh PersonOrganization Fit (P-O Fit), Motivasi Kerja, dan Kepuasan Kerja terhadap Komitmen Karyawan. Jurnal Aplikasi Manajemen, 10(2), h: 229238

Triaryati, Nyoman. (2003). Pengaruh Adaptasi Kebijakan Mengenai Work-Family Issue terhadap Absen dan Turnover. Jurnal Manajemen dan Kewirausahaan. 5 (1), pp: 85-96.

Utami, A. F., Bangun, Y. R., \& Lantu, D. C. (2014). Understanding the Role of Emotional Intelligence and Trust to the Relationship between Organizational Politics and Organizational Commitment. Procedia - Social and Behavioral Sciences, 115(Iicies 2013), 378-386. https://doi.org/10.1016/j.sbspro.2014.02.444. 